\title{
Teaching and Learning Psychology Ethics as a Meaningful and Enjoyable Experience ${ }^{\alpha}$
}

\author{
Yesim Korkut ${ }^{*}$ \\ Bilgi University, Clinical Psychology M.A Program, İstanbul
}

*Corresponding author. E-mail: yesimkr2@gmail.com

Background. It is crucial for psychology students and graduates to study ethics. However, neither teaching nor learning ethics is always an easy process. Course syllabi often include philosophical texts, specialized concepts, and numerous ethics or procedural codes. Could we consider all of this as a cognitive process? The students should be aware of all the vulnerabilities that can impact ethical decision-making, such as cognitive errors, emotional factors, social and organizational pressures, and situational factors.

There is a great deal of new research on the advantages of including emotional dimensions in the decision-making process (Decety \& Cacioppo, 2012; Decety \& Cowell, 2015); this research even claims that emotions strengthen the contribution of the cognitive process, and as a result enrich the final ethical judgments. Additionally, there is also a kind of hidden curriculum that we provide to students (Goold \& Stern, 2006; Hafferty \& Franks, 1994). It is exactly this area (internships, the way we relate to the students) to which we need to pay attention during their undergraduate and graduate years.

Conclusion. Expecting students to learn and internalize knowledge in a meaningful way necessitates new modes of instruction. Specifically, teaching and learning ethics in an interactive way, while paying attention to both good decision-making skills and emotional cues, would provide exactly what students would enjoy and learn from the most. In this article, we will suggest that, if the question is how to sensitize students to ethical issues in psychology, and in the profession, it is important to give them an active role and responsibility for disseminating ethical principles. We will also introduce different techniques that help combine knowledge with emotionality while teaching ethics in psychology.

\section{Keywords:}

psychology ethics; ethics in psychological practice; teaching ethics; teaching techniques; new methods; ethics course 


\section{Introduction}

Ethics course syllabi usually offer very rich philosophical texts, many ethics-specific concepts, and several exemplary ethics codes. According to Prentice (2014), although many students appreciate the need for lectures on basic ethical principles, some regard such lectures as dull rather than motivating.

It is clear that teaching only theoretical knowledge will not lead to full awareness and understanding of ethical issues. The main concern of this article is how we can make ethical knowledge more interesting and meaningful for our students and our colleagues. How can we successfully ensure that our students take on and carry forward an ethical understanding throughout their professional lives? The learning process surely has to be supported by other than academic means (Balogh, 2002) to achieve such a goal. Students learn best when they can emotionally connect to the subject, when they find meaning, and when they are active participants in the process. Let's start with the importance of the concept of values.

In essence, the ethical behavior of psychologists is based on values. Ethical codes translate professional values and beliefs into standards which define how the professional should act appropriately (Lindsay, 2008). On the one hand, values are largely determined by factors including religion, core beliefs, and culture. On the other hand, there are many universally shared values, such as fairness, and not harming others. It is to be expected that professional ethical codes would reflect both the values of psychologists which are shared internationally, and the culturally specific ones (Lindsay, 2008). Young psychology students especially need to understand the close relationships between the codes, cultures, and values. Exercises to discuss our individual values, cultural values, virtues, and ultimately professional values and how they relate to ethics, could well be included in the ethics curricula, as suggested by various scholars (Korkut, 2010; Sinclair, 2012; Pettifor, 2004; Pettifor, 1996; Pettifor, \& Ferrero, 2012).

We cannot give students theoretical knowledge on all possible ethical dilemmas and how to solve them all. They are expected to learn "ethical decision-making steps" to be employed while facing ethical dilemmas (Ruiz, 2009). To achieve this, we usually use models based on a rational understanding, such as the following example from Koocher and Keith-Spiegel (1998, pp. 14-15).

1. Determine that the problem is an ethical one.

2. Consult the codes of ethics or guidelines available for possible mechanisms of solution.

3. Consider which is the best possible decision.

4. Locate a trusted colleague with whom to consult.

5. Evaluate the rights, responsibilities, and vulnerabilities of all affected parties.

6. Generate a set of alternative decisions.

7. Enumerate the consequences of each decision.

8. Make the decision.

9. Implement the decision. 


\section{The role of emotions}

The above-mentioned rational decision-making steps are very valuable, but understanding ethical problems strictly as cognitive processes is not enough. Students should be aware of the vulnerabilities that can undermine ethical decision-making, such as cognitive errors, emotional factors, social and organizational pressures, and situational factors. Let's now have a brief look at what the literature suggests to us in that respect.

When people make ethical decisions, they have a tendency to consider immediate and concrete factors instead of more abstract ones (Glover, 2012). They tend to bring together, process, and remember information in self-serving ways (Langevoort, 1997). As an example, Prentice (2014) asserts that a person's views on gay marriage might well change if his or her child disclosed their sexual orientation. He gives as an example a senator who announced that he had switched from opposing gay marriage to supporting it, just because his son had announced that he was gay.

There is a great deal of research on the advantages of incorporating emotional aspects in the decision-making process (Decety \& Cacioppo, 2012). Empathy, for example, can have important consequences for decision-making (Decety \& Cowell, 2015). Emotions such as empathy, guilt, shame, anger, and disgust play a huge role in humans' ethical decision-making, and often lead people to make impulsive ethical judgments that they cannot rationally defend (Haidt, 2012). Kelly (2011) argued that the emotion of disgust evolved in order to keep people from eating poison and from exposing themselves to germs. Studies show that by simply subjecting people to a repulsive smell-spray in a room, or leaving used tissues around, the disgust emotion can be triggered. The result is a harsher ethical judgment than would otherwise have been exhibited.

Researchers can greatly change people's responses by showing them funny videos before they are presented with an ethical dilemma. Many similar studies show that emotions do strengthen the effect of the cognitive process and support the final ethical judgment. Therefore, it is a good idea to convince the students to realize that their ethical judgments and actions are not nearly as logic-based as they may seem. Although Sigmund Freud and his concept of the "unconscious" is not explicitly included in Nobel Prize winner Daniel Kahneman's (2011) work, Kahneman makes it clear that most human decision-making is done intuitively by what Kahneman calls "System 1." Most ethical decisions are made emotionally and intuitively before the cognitive parts of the brain ("System 2") take over.

It is critical for students to understand the role of emotions in moral judgments. Even well-trained, sensitive, mature psychologists can find themselves in risky situations, subject to unpredictable and unclear dilemmas, insufficient guidance, and loyalty pressures (Koocher \& Keith-Spiegel, 1998, pp. 6-10). Therefore, an important goal for ethics professors could be to challenge students with respect to their vulnerability to ethical mistakes. Maybe we are not as ethical as we think we are?

So, with these questions in mind, Prentice (2014) kept asking his students why anyone should care to act ethically. All of his students said they desired to act ethically, and they seemed to mean it. According to Prentice, the mind's ability to believe what it wants to believe is very strong. Thinking that a realistic worldview is 
much better than one based on an illusion, Prentice tried to convince his students through exercises that being ethical can be harder for them than they might expect. The main reason for unethical behavior is that the "want" self takes precedence. So the professor encourages his students to be aware of the conflicts between their "should" self and their "want" self.

In a similar fashion, one of the greatest problems is that people often use rationalizations to allow themselves to act unethically in certain situations. Greene (2014, p. 301) says, "Rationalization is the great enemy of moral progress." According to Anand, Ashforth, \& Joshi (2004), rationalizations act against moral intent. Therefore, all these authors point out that if we hear ourselves using rationalizations such as "If I don't do it, someone else surely will," we had better stop and think for a while and ensure we monitor ourselves carefully.

Sadly, most ethical mistakes are not made because people have not read enough ethics theory (Jennings, 2005). Rather, when those well-educated people make bad decisions, it is because of cognitive mistakes, social and organizational pressures, situational factors, and/or rationalizations like that mentioned above. Understanding these influences helps us to be aware of those factors that prevent people to engage in unethical behavior.

Drumwright, Prentice, \& Biasucci (2015) in their extensive review of the literature bring together many factors which can cause people to make decisions with serious ethical consequences without adequate consideration of the facts. For example, the desire to please the authorities can cause people to suspend their own ethical judgment. If the superior is unethical, people are capable of doing horrible things, as shown in the Milgram study (1963). In their article, those authors discuss that brain scans reveal that resistance to group pressure can be psychically costly: the pull to conform to the behavior of peers can be extremely powerful.

Individuals have a tendency to make different decisions depending upon how a question is framed. People will often make riskier and even less ethical decisions to avoid a loss than they would have taken to secure a gain. Many situational and environmental factors could adversely affect ethical decision-making in ways we do not even notice, such as time pressure and transparency. People are more vulnerable to ethical mistakes if they are tired, or if they feel depleted.

\section{Where to Teach Ethics?}

The discipline and science of psychology require sensitivity to ethical issues. Therefore teaching and training in ethics is a crucial component of the undergraduate psychology curriculum if we want students to learn ethics codes and behave ethically (Ruiz, 2009). Postgraduate studies provide the best opportunity to learn about conducting ethical research and all the basic ethical concepts. According to Fairman (2005), we try to train young researchers to employ ethical decision-making in their future work. Similarly, Wolpe (2010) claims that we want to train young scientists to recognize ethical issues when they arise and teach them the "tools" to cope with them.

Now I would like to come to some other opportunities for best planting the seeds of ethical values, and for paying attention to the emotional factors that could 
influence ethical decision making. The importance of learning ethics through modelling is huge. It is a well-known fact that if you tell a child not to lie, and as a parent, you yourself lie, the child will in fact do as you do, not as you say. The best learning is achieved by having "models" for morally-appropriate behavior.

Beside the teaching of the theoretical aspects, there is a hidden curriculum that we provide to students through our interaction with them, and this needs to be attended to during their undergraduate and graduate years. Residency settings and internships provide students with a great amount of experience (Goold \& Stern, 2006) and an opportunity for them to learn through experience. Hafferty \& Franks (1994) observe the positive effect of such a "hidden curriculum" among students. A study by Tabachnick, Keith-Spiegel, and Pope (1991) in the United States provided data from APA members working in institutions of higher education. The results showed the importance of their being "role models" for their students, providing examples of self-examination through an ethical lens.

But what exactly changes while we are teaching ethics? James Rest (1994) suggests that there are four key steps to acting ethically. First, people must perceive the ethical dimensions of an issue that they are facing (this is moral awareness). Second, they must have the ability to decide upon a course of action that is ethical (moral decision-making). Third, they must have the intent to act on that ethical decision (moral intent). Finally, they must have the motivation and courage to act upon that desire (moral action). Moral awareness is very critical here. Individuals are better prepared to make ethical decisions if they are aware of the related values and implications of the decisions they are facing (Moore \& Gino, 2013).

Drumwright, Prentice, \& Biasucci (2015) emphasize how teaching behavioral ethics can contribute in a meaningful way to improving ethics education. Understanding the above-mentioned cognitive errors, social and organizational pressures, and situational factors, could help enhance awareness of those factors that would eventually lead to unethical behavior. Teaching ethics, according to the authors, provides support for all the steps in Rest's (1994) model, from moral awareness to moral action.

Prentice's excellent review (2014) of research findings in the teaching of ethics revealed that problem-based learning was preferred by students over conventional teaching. Detailed case studies were useful in teaching ethical decision-making skills. Curricula which allow the active involvement of students in ethical decisionmaking, as opposed to more passive lectures, tended to best support the development of ethical judgment. Through activating teaching strategies such as group discussions, case analysis, and reflection sessions, students were able to apply ethical knowledge in real situations. Many of these findings show promise for improving students' ethics education and their future ethical behavior.

A similar finding comes from a recently completed study by Korkut and Aktas (2019). With the use of a book on teaching ethics which provides a series of CDs and visual material (Korkut, 2017), students were encouraged to role-play the scenarios provided in the classroom. Later, often in small groups, they discussed the vignettes while using a decision-making model. This method was used with the intent of helping students integrate ethical theory with their emotions, and to better understand how ethical conflicts arise. 
The study tried to evaluate the changes in the ethical behavior, moral values, and the adoption of ethical rules by the students as a result of the ethics curriculum, class practices, and exercises. Comparing pre-test and post-test applications of Dynamic Interpersonal Therapy (DIT), students who took the course showed an increase in post-conventional schema scores. Again, the pre-test and post-test comparisons showed that passive answers decreased, and active attitude answers increased significantly. Altogether, the results demonstrated the importance of psychology students taking a course on the acquisition of ethical values and knowledge, as well as being more active in terms of ethics.

\section{While Teaching Ethics, Which Techniques Should Be Employed?}

Expecting students to learn and internalize knowledge in a meaningful way necessitates unconventional methods. The content must be stimulating and motivating, and our teaching method should activate the emotions as well as rational thought. Let's have a closer look at different techniques that would help us to combine knowledge with emotionality while teaching ethics in psychology.

1. Case studies are an excellent basic method in learning ethics. By analyzing real situations, students can learn how to handle similar situations.

2. It is very efficient to break a class down into small groups and give them case studies to discuss.

3. Prentice (2014) says students consider reflective group discussions about dilemmas to be a technique associated with significant learning.

4. Stories (Levinson, 2015) which include ethical dilemmas as examples of the right and wrong ways to use one's skills, along with the outcome of each, grab students' attention. This method is most effective through debriefing the students.

5. Actual or past events with ethical aspects occurring at a given time in the society, or in the professional society, could be discussed in debates.

6. Balogh (2002) suggests using media journals (the discussion points there) as an interactive method.

7. Fisch (1997) suggests using films and movies which include ethical dilemmas such as a sexual intimacy problem with a client.

8. Role-playing is an excellent training technique for developing many interpersonal skills, including observing emotions and developing empathy. By assuming roles and acting out situations that might occur, students learn how to handle various situations before they face them in reality.

9. Technology provides new ways of learning. Using CD-ROMs or computer-based training is much more sophisticated than employing the original text-only programs. The new technologies provide stimulating graphics, audio, animation, and/or video. The Ethics handbook with two CDs from Turkey (Korkut, 2014) is an example.

10. A multimedia approach tends to be more provocative and challenging, and therefore more stimulating to the adult mind. Multimedia training materials are typically found in DVD format. 
11. Audioconferencing, tele- or videoconferencing allow the trainer to be in one location and trainees to be in remote locations. Lectures and demonstrations can be effective using this method.

12. Web meetings, or webinars, contain audio and visual components. They provide a chance for questions and interactive discussion with the presenter as well.

13. If the question is how to sensitize students to ethical issues in life and in the profession, one of the best methods is to give them an active role and responsibility in disseminating ethical knowledge. They could be encouraged to "create" their own projects or take part in larger projects related to ethics. For example, in Turkey we have published two books on ethics in psychological practice which include active contributions by students. In one project, students made a significant contribution to the preparation of instructional CDs and movies by role-playing some scenarios (Korkut, 2014). In another project, Ph.D students contributed to the translation of a book by Pope \& Vasquez (2016).

14. Last but not least, we should bear in mind that psychology is wedded to the social, cultural, political, and economic conditions of its times, as Danziger (1997) asserts. It is relevant to ask: "Where are we when trying to teach ethics to students? In what context are we teaching ethics?" The Zeitgeist, or socio-political spirit of the times, sometimes matters a lot.

Jeff Sugarman (2015) offers a critique and warns us that psychologists need to be ideologically aware if they are to comprehend their disciplines and professional practices ethically. Our students are not unaware of the problems surrounding us, and they observe our position in the face of them. Could we provide a space for discussion of the conflict situations that are emerging in the larger society or in the world? How can we as psychologists encourage our students, while we are teaching ethics, to also learn about cultural sensitivity, human rights, and environmental changes? The idea here is to nurture critical thinking skills during the lessons. Of course, since discussions would increase the uncertainty and the vulnerability in students, there is a need to first create a safe learning environment.

\section{Conclusion}

In sum, teaching and learning ethics in an interactive way, while paying attention to both rational decision-making skills and emotional aspects, would be exactly what students would enjoy and learn from the most. Once more, as Balogh (2002) and Schwartz ( 2002) nicely point out, a theoretical, cognitive emphasis on its own would not produce an enduring change in awareness and understanding of ethical issues. The learning process should be supported by other means.

To improve the quality of teaching and avoid "dryness," some strategies can be employed to help "generalize" the knowledge. The emotional factors influencing our ethical decisions, as well as the social and political circumstances and realities, can be carefully included in the learning process. All of these can make training deeper, more fun, and more enjoyable. Students can integrate theoretical knowledge with emotionality much more effectively, by all these means. 


\section{References}

Anand, V., Ashforth, B., \& Joshi, M. (2004). Business as usual: The acceptance and perpetuation of corruption in organization. Academy of Management Perspectives, 18(2), 39-53. https://doi.org/10.5465/ame.2004.13837437

Balogh, D.W. (2002). Teaching ethics across the psychology curriculum. American Psychological Society, 15, 7, 29-37.

Buxton, M., Phillippi, J.C., \& Collins, M.R. (2015). Simulation: a new approach to teaching ethics. Journal of midwifery \& women's health, 60(1), 70-74. https://doi.org/10.1111/jmwh.12185

Danziger, K. (1997). Naming the mind: How psychology found its language. London, UK: Sage.

Decety, J., \& Cacioppo, S. (2012). The speed of morality: a high-density electrical neuroimaging study. Journal of Neurophysiology, 108(11), 3068-3072. https://doi.org/10.1152/jn.00473.2012

Decety, J., \& Cowell, J.M. (2015). Empathy, justice, and moral behavior. The American Journal of Bioethics Neuroscience, 6(3), 3-14. https://doi.org/10.1080/21507740.2015.1047055

Drumwright, M., Prentice, R., \& Biasucci, C. (2015). Behavioral ethics and teaching ethical decision making. Decision Sciences Journal of Innovative Education, 13(3), 431-458. https://doi.org/10.1111/dsji.12071

Fairman, N., Crofut, A., \& Servis, M. (2012). "Crisis as a Classroom: Use of a Health Systems Crisis to Teach Ethics and Professionalism. Academic Psychiatry, 36(2), 138-141. https://doi.org/10.1176/ appi.ap. 10040059

Fisch, L. (1997). "Triggering Discussions on Ethics and Values: Cases and innovative case variations. Innovative Higher Education, 22(2), 117-134. https://doi.org/10.1023/A:1025145407445

Glover, J. (2012). Humanity: a moral history of the 20th century (2d. edition). New Haven, CT: Yale University Press.

Goold, S.D., \& Stern, D.T. (2006). Ethics and professionalism: what does a resident need to learn? The American Journal of Bioethics, 6(4), 9-17. https://doi.org/10.1080/15265160600755409

Hafferty, F.W., \& Franks R. (1994). The hidden curriculum, ethics teaching, and the structure of medical education. Academic Medicine, 69(11), 861-871. https://doi.org/10.1097/00001888-199411000-00001

Haidt, J. (2012). The righteous mind. New York: Pantheon Books.

Jennings, M. (2005). Ethics and investment management: true reform. Financial Analysts Journal, 65(3), 45-58. https://doi.org/10.2469/faj.v61.n3.2727

Kahneman, D. (2011). Thinking: Fast and slow. New York: Farrar, Straus \& Giroux.

Keith-Spiegel, P., Whitley, B. E., Jr., Balogh, D.W., Perkins, D.V., \& Wittig, A.F. (2002). The Ethics of Teaching: A Casebook. Second Edition. Psychology Press.

Kelly, D. (2011). Yuck! The nature and moral significance of disgust. Cambridge, MA: MIT Press. https://doi.org/10.7551/mitpress/8303.001.0001

Koocher, G. \& Keith-Spiegel, P. (1998). Ethics in Psychology, New York: Oxford University Press.

Korkut, Y. (2010). Developing a national code of ethics in psychology in Turkey: Balancing international ethical systems guidelines with a nation's unique culture. Ethics \& Behavior, 20(3-4), 288-296. https://doi.org/10.1080/10508421003799057

Korkut, Y. (2017). Psikologlar için Etik Öğretim El Kitabı. İkinci baskı. Ankara: Türk Psikologlar Derneği Yayınları.

Korkut, Y. \& Aktas, A. (2019). Teaching Psychology Ethics in Turkey: The Evaluation of a Practical Study in Terms of Ethical Behavior, Moral Values and Adoption of Ethical Rules. Journal of Clinical Psychology Research, 1-14. https://doi.org/10.5455/kpd.2602443816052019m000011

Langevoort, C. (1997). Organized illusions: A behavioral theory of why corporations mislead stock market investors (and cause other social harms). University of Pennsylvania Law Review, 146(1), 101-172. https://doi.org/10.2307/3312706

Levinson, M. (2015). Moral injury and the ethics of educational injustice. Harvard Educational Review, 85(2), 203-228. https://doi.org/10.17763/0017-8055.85.2.203

Lindsay, Geoff, (2008). Chapter 1, Professional Ethics and Psychology. In Lindsay, G., Koene, C., Øvereeide, H., \& Lang, F. (Eds.), Ethics for European psychologists. Hogrefe Publishing. 
McCarron, M.C.E., \& Stewart, D.W. (2011). A Canadian perspective on using vignettes to teach ethics in psychology. Canadian Psychology/Psychologie Canadienne, 52(3), 185-191. https://doi.org/10.1037/a0024504

Moore, C., \& Gino, F. (2013). Ethically adrift: How others pull our moral compass from true North, and how we can fix it. Research in Organizational Behavior, 33, 53-77. https://doi.org/10.1016/j.riob.2013.08.001

Pettifor, J.L. (2004). Professional ethics across national boundaries. European Psychologist, 9(4), 264272. https://doi.org/10.1027/1016-9040.9.4.264

Pettifor, J.L. (1996). Ethics: Virtue and politics in the science and practice of psychology. Canadian Psychology/Psychologie canadienne, 37(1), 1. https://doi.org/10.1037/0708-5591.37.1.1

Pettifor, J.L., \& Ferrero, A. (2012). Ethical dilemmas, cultural differences, and the globalization of psychology. In M.M. Leach, M.J. Stevens, G. Lindsay, A. Ferrero, \& Y. Korkut (Eds.), Oxford library of psychology. The Oxford Handbook of International Psychological Ethics, 28-41. https://doi.org/10.1093/oxfordhb/9780199739165.013.0003

Pope, K.S., \& Vasquez, M.J. (2016). Ethics in Psychotherapy and Counseling: A Practical Guide. John Wiley \& Sons.

Prentice, R.A. (2014). Teaching behavioral ethics. Journal of Legal Studies Education, 31-2, 325-365. https://doi.org/10.1111/jlse.12018

Rest, J.R. (Ed.). (1994). Moral development in the professions: Psychology and applied ethics. Psychology Press. https://doi.org/10.4324/9781410601162

Ruiz, A (2009). Ethics in the Introduction to Psychology Course. Observer, 22(5). Retrieved from: http://www.psychologicalscience.org/index.php/publications/observer/2009/may-june-09/ ethics-in-the-introduction-to-psychology-course.html

Sinclair, C. (2012). Ethical principles, values, and codes for psychologists: An historical journey. In M.M. Leach, M.J. Stevens, G. Lindsay, A. Ferrero, \& Y. Korkut (Eds.), Oxford library of psychology. The Oxford handbook of international psychological ethics (pp. 3-18). New York, NY, US: Oxford University Press. https://doi.org/10.1093/oxfordhb/9780199739165.013.0001

Sugarman, J. (2015). Neoliberalism and psychological ethics. Journal of Theoretical and Philosophical Psychology, 35(2), 103. https://doi.org/10.1037/a0038960

Tabachnick, B.G., Keith-Spiegel, P., \& Pope, K.S. (1991). Ethics of teaching: Beliefs and behaviors of psychologists as educators: American Psychologist, 46(5), 506. https://doi.org/10.1037/0003-066X.46.5.506

Tversky, A. \& Kahneman, D. (1991) Loss Aversion in Riskless Choice: A Reference-Dependent Model, The Quarterly Journal of Economics, 106(4), 1039-1061. https://doi.org/10.2307/2937956

Wolpe, P.R. (2010). Teaching Ethics to Basic Scientists: Suggestions for Greater Curricular Clarity. The American Journal of Bioethics, 2(4), 62-63. https://doi.org/10.1162/152651602320957646

Original manuscript received November 26, 2019

Revised manuscript accepted December 24, 2019

First published online March 15, 2020

To cite this article: Korkut, Y. (2020). Teaching and Learning Psychology Ethics as a Meaningful and Enjoyable Experience. Psychology in Russia: State of the Art, 13(1), 33-41. DOI: 10.11621/ pir.2020.0104 